\title{
An e-REAL Lab in Dubai. Immersive Experiences, Visual Communication and Augmented Reality
}

\author{
http://dx.doi.org/10.3991/ijac.v8i3.4912 \\ Fernando Salvetti \& Barbara Bertagni \\ LKN-Logos Knowledge Network, Bern and Lugano, Switzerland
}

\begin{abstract}
REAL is an enhanced reality lab by LKN and is at the forefront by design for learners' centricity. It is becoming a cornerstone as a suite of solutions based on immersive experiences, visual communication and augmented reality. e-REAL is both a physical and a virtual ecosystem for boosting people and fostering their competencies: it embeds augmented reality tools, mobile applications, holograms and wearable devices to be used during education and training programs, as well as being utilized for assessment and development centers. e-REAL can be delivered both face to face and remotely. By implementing e-REAL, a myriad of competencies are fostered and audited: this includes behavioral skills, as well as cognitive and metacognitive capacity. Technical know-how and job-related competencies are also honed and attested. As a result, people's performance is expected to grow; measuring return on investment and the outputs in terms of competencies' growth is an easy task; the most demanding traceability standards are guaranteed.
\end{abstract}

Index Terms-Augmented Reality Tools, Boosting and Assessing Performance, Holograms, Visual Thinking and Edugraphics, Wearable Devices, e-REAL.

\section{Boosting Growth, DeVElopMent AND Social PROGRESS WITHIN THE KNOWLEDGE SOCIETY}

The $21^{\text {st }}$ century world is really different from the one that principal education systems were designed for. It is not possible anymore to continue offering education and training in the traditional way. We need to educate and train people to have a general aptitude for identifying and dealing with flows, complex dynamics and systems thinking. And we need to develop people's analytical and cognitive competencies, as well as meta-cognitive abilities, allowing them at any level to make connections between "pieces of knowledge" that can be very far removed from each other.

During the last two centuries, modern economic growth and the diffusion of knowledge have made it possible to avoid the "Marxist apocalypse," but have not modified as much the deep structures of capital. When the rate of return on capital exceeds the growth rates of output and income, as it did in the $19^{\text {th }}$ century and seems quite likely to do again in the $21^{\text {st }}$, capitalism generates arbitrary and unsustainable inequalities - this is also seen in the stock of skills distributed in the population that undermine the "meritocratic" visions and perspectives that are assumed to be among the grounding pillars of our world [1].
The separation between capital accumulation and "learning" is not a clean one: knowledge is a form of capital, but with distinctive properties [2]. Knowledge is not the result of a passive transmission of information, but the product of personal and interpersonal exchange. Knowledge is constructed within the context of a person's actions, so it is "situated": it develops in dialogic and interpersonal terms, through forms of collaboration and social negotiation. Significant knowledge and know-how is the result of the link between abstraction and concrete behaviors in order to make the intangible more tangible. Knowledge and action can be considered as one: facts, information, descriptions, skills, know-how and competence acquired through experience, education and training. Knowledge is a multifaceted asset: implicit, explicit, informal, systematic, practical, theoretical, theory-laden, partial, situated, scientific, based on experience and experiments, personal, shared, repeatable, adaptable, compliant with socio-professional and epistemic principles, observable, metaphorical and linguistically mediated. Knowledge is a fluid notion and a dynamic process involving complex cognitive and emotional elements for both its acquisition and use: this includes perception, communication, association and reasoning. In the end, knowledge derives from minds at work. Knowledge is socially constructed, so learning is a process of social action and engagement involving ways of thinking, doing and communicating [3].

Because our world is mainly a knowledge society "glocal," liquid, networked, virtual and polycentric building a learning mindset among people should be one of the major objectives for both government and for socially responsible companies, firms and organizations. Learning touches every aspect of a modern dynamic economy and does even more so concerning an emerging market struggling to become an advanced knowledge society. What separates developed from less-developed countries is not just a gap in resources, but a gap in knowledge. There is no "natural," spontaneous process to increase a learning mindset within a society: multinational companies and international organizations can convey knowledge across borders and highly skilled people move as well, but there is no evidence that markets are efficient in the production and dissemination of knowledge and learning. The knowledge of various factors that affect returns on invested capital and that is required to use capital efficiently, doesn't move perfectly across borders; neither does knowledge about how effective a particular enterprise is in using various inputs to produce and market outputs. Still, there are numerous aspects of tacit knowledge, about how individuals and organizations in- 
teract with each other and norms of behavior, that affect economic performance and how they learn and adapt: such tacit knowledge does not move easily across borders - nor among or within organizations.

Government has a responsibility in creating a knowledge society and socially responsible organizations as well. There is an important role for government to play in shaping an innovative economy and in promoting a learning mindset. It is often through new investments that new ideas are discovered and new research is "embodied." If the pace of investment determines the pace of learning, then of course it is impossible to neatly separate out what part of the increase in productivity is a result of capital accumulation and what part is a result of improvements in technology, because the two are inextricably intertwined. Therefore, creating and sustaining a learning society should be one of the major objectives relevant to both government and socially responsible organizations. Increasing the ability and the incentives to learn, learning how to learn and then closing the knowledge gaps that separate the most productive countries, firms and organizations from others, largely accounts for the ever-rising standards of living in successful economies. The transformation to learning societies which occurred around the $19^{\text {th }}$ century for Western economies and more recently for those in Asia, appears to have had greater impact on human well-being than improvements in allocative efficiency or resource accumulation. If that is so, creating and sustaining a learning society should be one of the central preoccupations for both governments, economic actors, education and training experts, and social scientists.

Knowledge and skill-sets, like information, are asymmetric. Not only do firms and societies differ in their ability to transform inputs into outputs, they also differ in their knowledge and they differ in their ability to learn. Some individuals, firms and countries are quicker at picking up changes that have occurred elsewhere, discovering or building knowledge that might be relevant and adapting or developing technology to their circumstances. Each country and each organization makes decisions regarding what it will learn about. There are benefits from specializations and economic analysis may provide guidance about comparative advantages related to specialization. But there are skills that are of great value within any environment, country or organization: soft-skills, cognitive and meta-cognitive skills. Those skills need to be boosted all around the world. Then there are skill-sets that are of special relevance, but particularly scarce in some ecosystems, such us entrepreneurship [4].

The e-REAL lab installed at Etisalat Academy in Dubai [5] is at the heart of an ecosystem aimed at boosting knowledge and learning abilities, including the ability to learn and to learn how to learn. e-REAL is at the forefront by design and is transforming the way in which people, organizations and businesses perform. It stands for Enhanced Reality Lab and is a place to experience challenging situations in a small group setting, engaging all participants simultaneously on different levels: with peers, thematic experts and learning facilitators - both on-site and remotely. e-REAL is a lab based on visual thinking and knowledge visualization, facilitated by enhanced - or augmented - reality tools. It is a highly interactive and face-to-face lab that promotes proactive data and information research. Everything is available, but learners have to actively look for it. It allows knowledge sharing with remote teams, as well as interactive and cooperative elearning. In the image below, a representative e-REAL lab is shown, highlighted with some commentary to provide a deeper understanding in regards to some of the tools available in the immersive room.

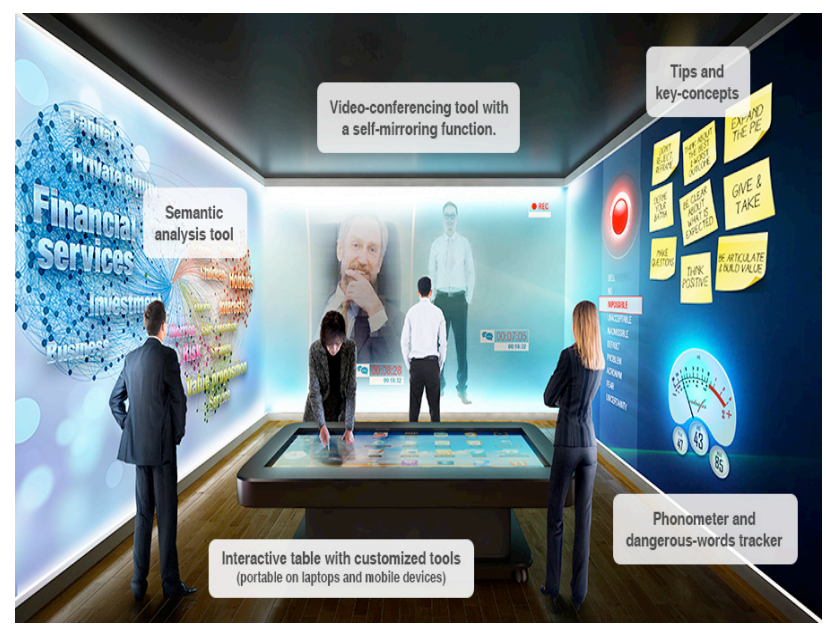

Accordingly with the outputs from our first survey, the e-REAL in Dubai is very beneficial for boosting best practices and it's an ideal catalyst for learning. To summarize the major outputs, we can say that learning occurs in a context: we mainly learn by doing and we also learn from others - both in formal education and in training and, even more importantly, in everyday contact with others. eREAL is becoming a cornerstone, relevant also for sharing tacit knowledge - understandings that are hard to codify, to articulate as simple prescriptions that can be easily conveyed through textbooks or classroom learning.

\section{EDUCATIONAL TRENDS AND SCENARIOS}

By the $20^{\text {th }}$ century, all major industrialized countries offered formal education and training to their populations. When the curricula took shape in the $19^{\text {th }}$ and $20^{\text {th }}$ centuries, scientists didn't know very much about how people learn. Even by the 1920 s, when schools began to become the large bureaucratic institutions that we know today, there still was no sustained study of how people learn. As a result, the major parts of the educational institutions we have today were designed around commonsense assumptions that had never been tested scientifically [6].

Today, in our networked, liquid and "glocal" society, we know that all over the world current buzzwords include complex problem setting and solving, communications, creativity and innovation, flexibility, soft skills, contextual and cross-cultural intelligence - these exist at any level and as an output of any educational and training process. We should consider any educational setting and ecosystem, as well as the human mind, to be complex systems. While the $19^{\text {th }}$ and the $20^{\text {th }}$ centuries were, in education and training, mainly about standardization, the $21^{\text {st }}$ century is mainly about systems thinking, visualization, customization, cheapification, gamification and some other relevant trends summarized below.

a) Making knowledge visible as well as making more tangible the intangible: what really matters is helping people to learn by making visible the deep knowledge they need to learn - often with simple and intuitive apps based on sophisticated technologies. 
b) Mobile, informal, collaborative and lifelong: four qualifiers that are very worthy when it comes to fostering people development, self-empowerment and employability in today's "glocal" world.

c) Learning how to learn matters more than learned content.

d) A learner centrist design, as well as learning in online communities.

e) Maria Montessori. Still a landmark in education, interesting in many regards, including the field of vocational training.

f) Finland. The Ministry of Education has created a vision that stresses collaborative teaching and learning, networking and teamwork.

g) Singapore's Master Plan for IT in Education: it integrates computers into all aspects of education, with the goal of helping students to think flexibly, creatively and collaboratively.

h) Motivation and cognitive engagement in learning environments.

i) Neurobiology of learning: facilitating learning, retention, recall and effective use and application of learned information by the insights gleaned from neurobiological and cognitive neuro-scientific experimentation.

j) Scientists realize learning is not simply trying to help students better memorize textbook facts, because memorizing isolated facts and step-by-step procedures is not enough in today's world. This is a world that is in need of people who are enabled to deal with system's thinking and complex, real-world problems.

k) Flipped classrooms, differentiated instruction and project-based learning.

1) Just-in-time skills acquired mainly on the job and by informal learning, modular and skill based education.

$\mathrm{m})$ The boundary between formal schooling and continuing education will increasingly blur. The milestone of a high school diploma could gradually decrease in importance as the nature of learning in schools begins to look more and more like an on-the-job apprenticeship and adult distance education.

n) Today's standardized tests are deeply flawed, because they assess only the surface knowledge emphasized by "instructionism" and do not assess the deep knowledge required by the "glocal" world. For example, mathematics tests do not assess model-based reasoning; science tests do not assess whether preexisting misconceptions have indeed been left behind, nor do they assess problem-solving or inquiry skills.

o) The video-game industry is a leader in holding mainly young people's interests and getting them to acquire all sorts of arcane skills, at vastly lower costs than the educational system.

p) Between now and 2018, we'll see the number of smartphones, tablets and other connected devices skyrocket.

q) We are approaching the era of personal cloud, software-defined anything, as well as the Internet of everything, smart machines and $3 \mathrm{D}$ printing.

r) The wall separating school and life needs to be broken down: people may leave school for the real world sooner and that doesn't mean an end to learning.
Lifelong learning matters and there should be calls for multiple educational activities distributed over a lifetime.

s) We are interconnected in a polycentric world more than ever. Connecting global talents across time and space is a must.

t) MOOCs: virtualization of education on a mass scale. It's too early to tell if and how massive online open courses will affect the landscape of education, but the sector has indeed been forever changed.

u) App mindset. Apps are shortcuts designed for accomplishing specific tasks. They're ubiquitous, powerful and strongly structured. The app mindset motivates youth to seek direct, quick, easy solutions the kind of answers an app would provide. People growing up in our time are not only immersed in apps, they've come to think of the world as an ensemble of apps.

v) Multiple intelligences. People have many different and discrete facets of cognition, so they have different cognitive strengths and contrasting cognitive styles. A radically different view of the mind and intelligence that yields a very different vision of education is needed.

A revolution is under way due to a number of big changes that are emerging at the same time: high-speed mobile networks, cheap tablet devices, the ability to process huge amounts of data cheaply, sophisticated online gaming, adaptive-learning software, "stellar" contents available for free and "superstar" lecturers and experts are remotely available. At its heart is the idea of moving from a "one-size-fits-all" education, to a more personalized approach, with technology allowing true human-centric processes to enhance learning by utilizing augmented reality tools. The job of the classroom's teachers and trainers, at every education and training stage, will move from orator to coach and learning facilitator, while using adaptive computer programs and augmented reality tools allowing each learner to be actively engaged at his or her own pace.

\section{E-REAL AS A COMPETENCE-BOOSTER BY THE PRIMACY OF PERCEPTION, VISUALIZATION AND EDUGRAPHICS}

e-REAL is part of an educational revolution, being at the forefront by design and aligned with the major trends summarized above: as an innovative ecosystem based on visual thinking and immersive learning, as well as augmented reality tools, advances in tablet technology and mobile applications, wearable devices and custom multimedia libraries, it is successful in boosting - as well as auditing - individual's knowledge, skills and abilities allowing interactive and cooperative learning, face-to-face and remotely.

Integrating training on soft skills with those that are technical and specialized is a major aim. By utilizing eREAL, a myriad of skills are fostered and audited: this includes both behavioral and cognitive, as well as metacognitive skills. Finally, technical skills are also honed and attested.

Learning happens through being immersed in a context. Our departure points can be summarized by the title of a book by Maurice Merleau-Ponty: The Primacy of Percep- 
PAPER

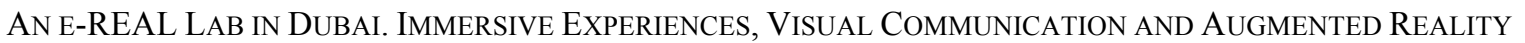

tion [7]. Experience is lived and perceived as a focal point and as a key crossroad. e-REAL is characterized by the primacy of perception, backgrounds, and emotions, in counter position to a well-founded tradition based not only on an epistemology and a vision of science that is rather naïve (positivism, as "neo," or not as it may be), but also as a much criticized "metaphysical" thesis relating to human beings: dualism (as Cartesian, or not, as it may be) and the clean mind-body separation. This includes the body or "physical substance," with its chemical, pneumatic, mechanical and electrical mechanisms; and the mind with its thoughts, sentiments, memories and images; made up of a totally separate "mental substance." Even if the Cartesian body-mind dualism historically lost its attraction very early on, the notion that mental life is "internal," separate from behavior, which is "external," survived much longer and can still be found today in many psychological, pedagogical and andragogical approaches. With the consequences, often experienced by those who attend schoolrooms, universities, professional and corporate training centers and business schools, of uniting and managing impoverished, simplified models and conceptual human actions that cannot be used in the dense and polysemic dynamics of our daily lives.

Perhaps it is no coincidence that we still often bring into account learning approaches that, doing a little archaeology of knowledge, we could trace back to the model of the Panopticon, described by Jeremy Bentham, or rather prison (and then hospital, factory or learning institutions), "that shows everything" thanks to the spoke shape of the building: an environment where ideally a single observer may watch everything all the time, adding to the perceptions of the inmates (or patients, workers, students), a sort of omniscience and generalized control by the guardian [8]. This occurs in an environment - the Panopticon where learning is conceived as a passing of information from the lecturer to the student, following a communicative process that tends to be one-way (top-down) and within which the "retroactions," feed-back (bottom-up), take on the role of interrogations. Panoptism is a philosophy and a vision-guide. The discipline is a base assumption of the psycho-pedagogical procedures; Taylorism (and its many "neo" variations) as an organizational model. But the Panopticon is not exactly the type of benchmark to look towards for inspiration, unless you wish to "re-edit" Charlie Chaplin in "Modern Times," or any other form of neo-taylorism.

What we need - in universities and schools, but above all in public and private organizations, active both in profit markets as well as in non-profit contexts - are new ways of thinking, which are able to process peculiarities, individualities, oddities, discontinuities, contrasts and singularities. Ways of thinking that are able to understand the variety and plurality of belonging; and ways of being part of the many local worlds in which we live, study and work. We need to learn how to learn a potentially relativist (but not destructive or nihilistic), relational and selfaware thought that knows its requirements and that is left unsaid. A thought that is able to consider the cognitive restraints that make it up; that sometimes command and control it blindly and fideistically. A thought that is aware that knowledge is a mélange of rationality and rationalization; of true and false intuition, inductions, syllogisms and paralogisms, ways of saying and doing things, personal opinions and shared beliefs [9].
e-REAL is an ecosystem: an ever-expanding system of immersive experiences, apps \& tools - where hundreds of contents are available off-the-shelf. It is a visual, eye catching, attention attracting, immersive and amazing ecosystem. e-REAL comes packed with a starter kit that enables learners to do many activities using gestures and spoken commands. Moreover, it can be customized with a number of exceptional multimedia contents and augmented reality tools: 2D and 3D multimedia libraries, interactive tutorials and cases, wearable devices and augments, holographic visualizations, real-time and live holograms broadcasted from everywhere (thanks to an easy solution with a low consumption of broadband). All of it is easy, simple and effective: in the lab one button manages everything and the staff that manages it remotely is able to control all the details. e-REAL contains a number of multimedia libraries, a suite of apps and tools available for on the job, then on a platform where it is possible to teach every branch of human knowledge with motion pictures, as well as with images, movies, holograms and augmented reality tools. It's quite a "futuristic" environment. Visual thinking, digital technologies and knowledge visualization are transforming the way in which people learn by opening up new opportunities for immersive training.

Do you ever feel completely overwhelmed when you're faced with a complex problem while you are learning? In learning, complex doesn't always equal complicated. Learning implies coping with complexity, but a good educational methodology allows learners to learn in a simple way. Simplified learning doesn't mean impoverished concepts and reasoning, but, on the contrary, making complexity graspable.
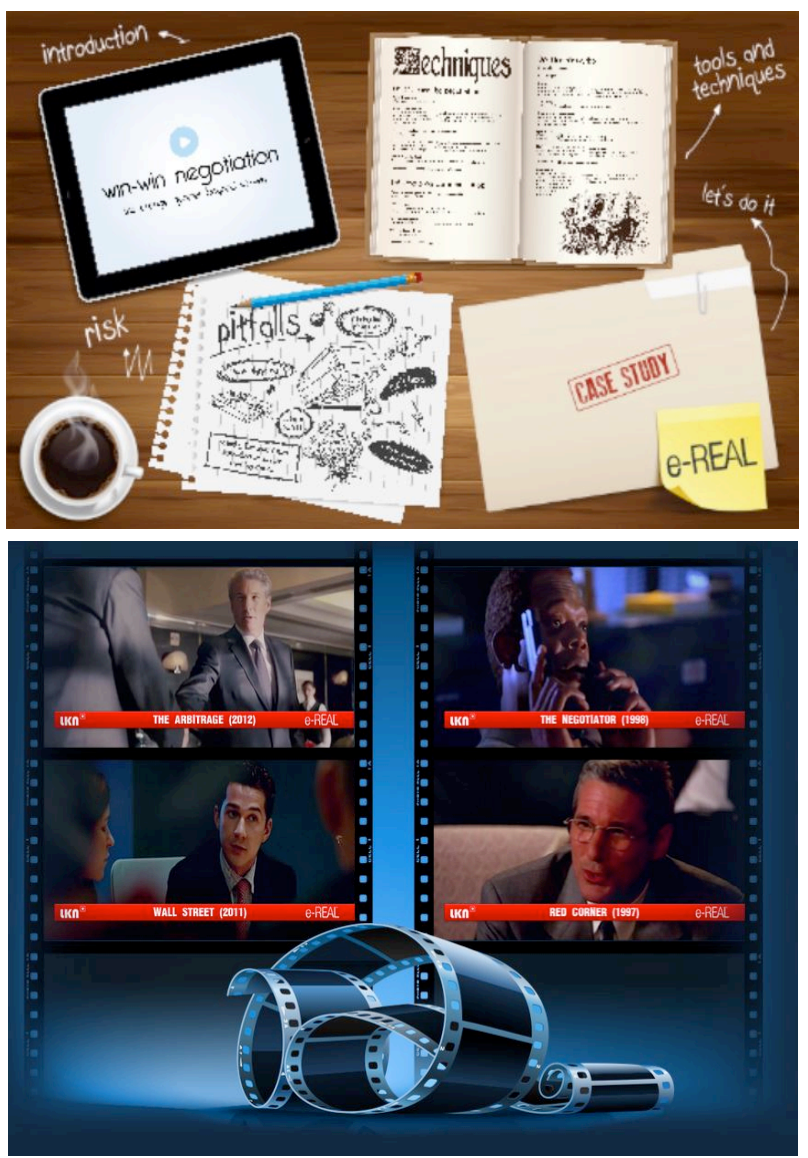
An effective visualization is the key to help untangle complexity: the visualization of information enables us to gain insight and understanding quickly and efficiently. Examples of such visual formats are sketches, diagrams, images, objects, interactive visualizations, information visualization applications and imaginary visualizations as in stories [11] and as shown in the two frames above. These are from a program on negotiation and closing deals at an international level delivered several times in Dubai.

As humans, we have a very well developed sense of sight: half of our brain is devoted directly or indirectly to vision. Images are able to grab our attention easily. We process images very quickly: researchers suggest that people process visuals 60,000 times faster than text. This is the reason why we are confronted with an immense amount of images and visual representations every day: digital screens, advertisement, messages, informationcharts, maps, signs, video, progress bars, diagrams, illustrations, etc. If we have to warn people, symbols and images are excellent: they communicate faster than words and can be understood by audiences of different ages, cultures and languages [12].

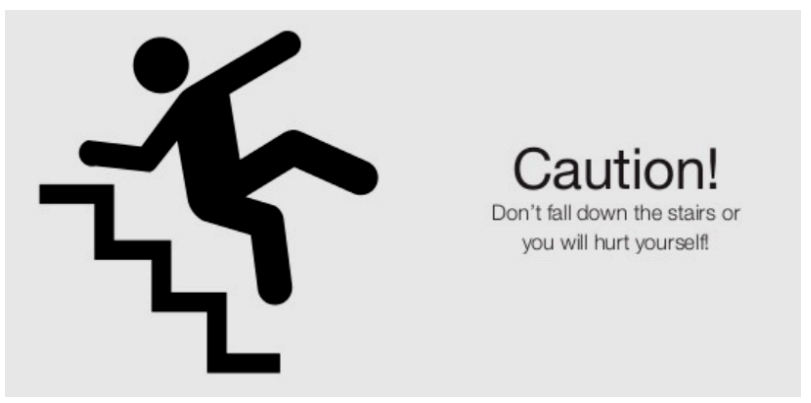

Images are powerful: we know that people tend to remember about $10 \%$ of what they hear, about $20 \%$ of what they read and about $80 \%$ of what they see and do.

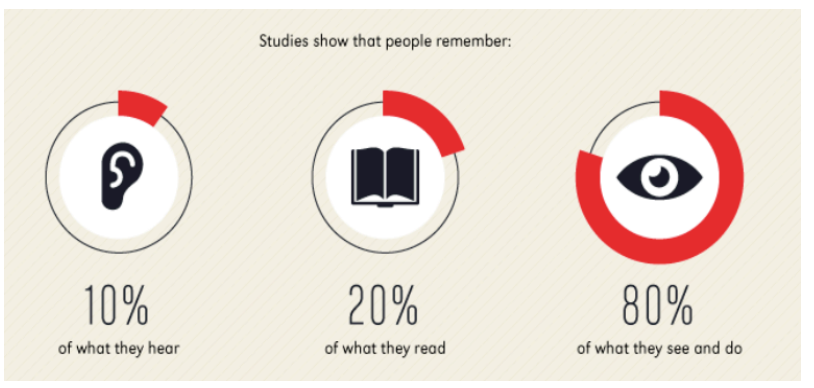

So, in education and training, images are often used like illustrations, to give a better understanding of a text and to promote memorization. Within e-REAL, a different way to design is promoted by visualization for education and training that is much more powerful than a simple illustration: a visualization that allows learners to have a first understanding that stimulates curiosity, shows relationships between topics, activates involvement, generates questions they didn't think of before and that facilitates memory retention. The challenge faced in e-REAL is being able to create visualizations that act like concept maps and that help organize and represent knowledge on a subject in an effective way, similar to infographics helping us understand information in dynamic ways and edugraphics helping learners enhance learning.
Edugraphics are the infographics used in the e-REAL ecosystem: not simply illustrations, but an innovative way to present a subject with a larger graphic design that combines data visualizations, illustrations, text and images together into a format that tells a complete story. A good infographic must be unique and impactful, or it won't be memorable to the audience. There are different forms of infographics: static, zooming, clickable, animated, video and interactive. The more they are interactive and dynamic, the more powerful and effective they are. Let's take as an example "Land/Sea" by Karl Tate. This infographic shows us our world from the tallest mountain to the deepest ocean trench in a unique snapshot.
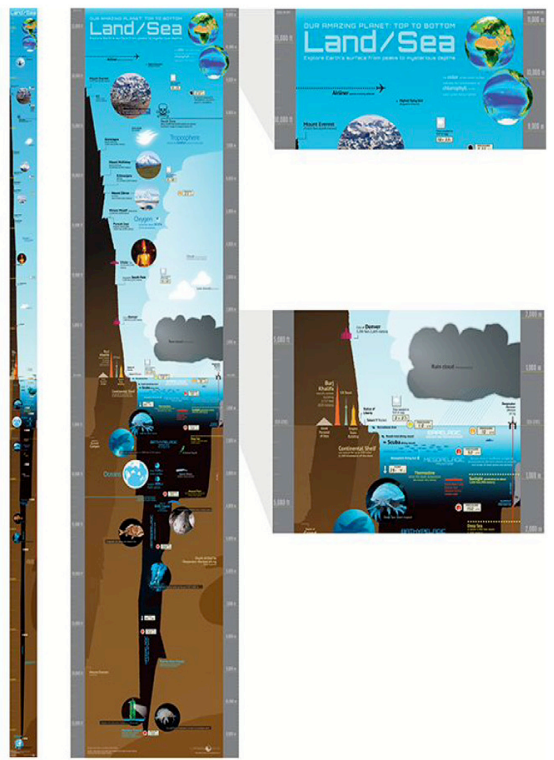

Looking at the image, we gain an immediate first level of understanding, but the success of the graphic is that it stimulates our investigation: a lot of questions arise from the visual exploration of the image. So, what are the characteristics of an effective edugraphic?

a) It is a graphic visual representation of information, data or knowledge that makes complex topics easy to be understood - showing us the trends and implications that underlie data.

b) It combines data visualizations, illustrations, text and images together in an interesting, eye-catching and engaging way, increasing learners' attention, understanding and memorization of the topics.

c) It must support a personal exploration from different perspectives: a unique snapshot with a possibility to embrace all the complexity of the topic, zooming out for a global vision and immediately zooming in on a simple detail.

d) It works like storytelling, telling complete stories and putting information in a context showing relations and comparisons, to make the topics easily understandable and to promote critical thinking.

e) It works like a concept map extracting the patterns that underlie data and information, helping us to think in terms of the bigger picture, of the patterns that reside within the information.

The best edugraphics are interactive: they can be presented by the trainer or the teacher and then learners can 
discuss in small groups and study in-depth the topics on the web and in books. The e-REAL setting allows a very innovative and effective way to enhance the learning experience by the use of visuals: learners can explore the images by touching them - with a complete involvement of mind and body. Conceptual maps and interactive edugraphics are presented showcasing the main concepts of visual case-studies, realistic scenarios, movie clips, interactive mosaic areas fully loaded with visual contents to explore, visual instructions and video monitoring and the mirroring of facial expressions and body language. All is visualized in order to immerse learners in an augmented reality setting, to foster comprehension, awareness and learning.

In all these cases, the edugraphics are prepared in advance. But it is also very engaging to have someone facilitating the learning process by a graphic facilitation: translating complex ideas into words and pictures in real time during meetings and lessons.

Another interesting use of visualization is utilized by asking learners to become active and visualize by themselves topics. This offers them an excellent opportunity to gain a profound understanding of concepts.

\section{Boosting SKILls By IMMERSIVE LEARNING}

As information technologies evolve, so do the possibilities for more immersive learning and teaching techniques. e-REAL is using cutting edge technologies to create both a virtual and a physical ecosystem, which immerses people in real life situations (e.g. negotiation with a client, opening a new shop abroad, crisis management or decision making within a networked virtual team), with possibilities to interact simultaneously with peers, tutors and learning facilitators, thematic experts and colleagues (both on-site and remotely), as well as consulting literature, records and other written information (that are available as multimedia content).

Much like being immersed within a videogame, people are challenged by facing real cases within complex scenarios that present a "more than real" wealth of information. This is because the many levels of the situation are made available simultaneously. e-REAL submerges learners in an immersive reality where the challenge to be tackled is created by sophisticated, interactive computer animation in three dimensions and holographic projections. It further includes live and real time interaction with peers, trainers, tutors, facilitators and mentors. And thus, it adds a very important social component that enhances learning outputs, as well as metacognitive processes (and skills).

The primary concepts and issues of a particular case can be dealt with by visualizing them with the use of holograms (to be seen without 3D glasses or any particular tool), on big screens, or by projecting them directly on walls, ceilings and floors. By moving the body, or with a flick of the hands, people can experiment with dynamic images, sound and vision, including holograms and 3D visualizations; all creating a profound emotional impact. The process of "learning by doing" within an immersive lab, based on knowledge visualization by interactive surfaces (walls, mobile devices, electronic tables, etc.), leaves the attendees with a profound and memorable experience. Attendees are challenged both cognitively and behaviorally in a fully-immersive and multitasking learning envi- ronment. e-REAL is an ideal educational environment in order to foster and audit both technical and soft skills that are competency related, as well as cognitive and metacognitive skills.

Moreover, e-REAL is an environment that immerses the learners in an "augmented" reality where real life situations can be really lived (not only simulated) and the necessary lessons learned without the disadvantage of a negative impact in case of mistakes. e-REAL is very good with regards to constructivism in education, which showcases that learning is a process of social action and engagement involving different ways of thinking, doing and communicating. Learning is a form of participation in social environments aimed at "co-constructing" knowledge: learning is an interactive, highly contextual process that leads to new interpretations of the world and creates a social fabric.

\section{BoOsting SKILls BY TOOLS}

There are many tools available within the e-REAL lab that are aimed at making people more aware regarding the different emotions they are experiencing - primarily by linking the subjective experience of emotions to associated behavior and physiological changes involving the autonomic nervous system and the endocrine system, as well as by monitoring the interpersonal effects of facial expressions, tone of voice and body postures (verbal and notverbal communication). Knowing that we are affected in many ways as well by other people's emotions and emotional expressions, some of the tools currently in use within e-REAL are aimed at focusing on the social context that frames the emotional phenomena. Because emotions adjust our mental and bodily states to cope with the challenges detected in the environment, within e-REAL we deal with both relevant physiological specificity and people's interpretation of their own emotions.

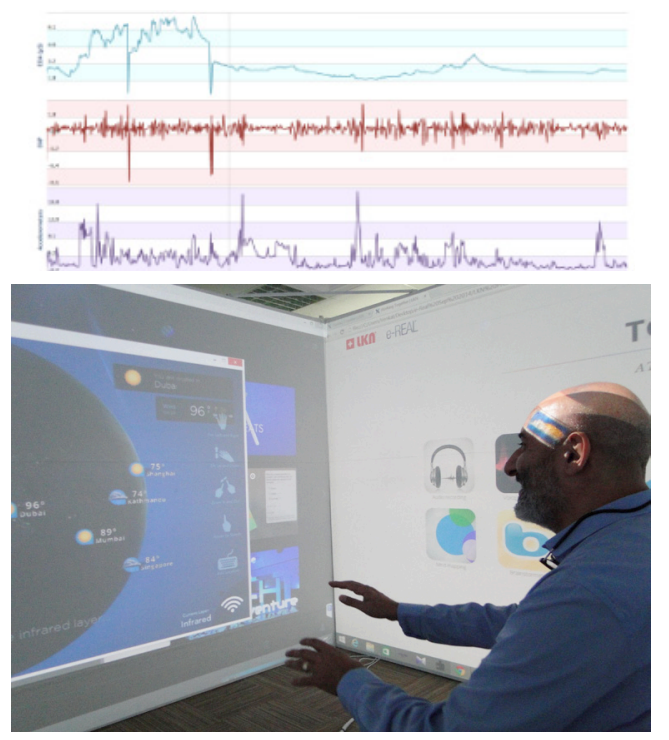

We are used to working with a number of tools in order to monitor physiological signals in real time, to track people's stress and other biometrics to capture facial expressions analyzing the correlated emotional answers. At the same time, other tools are usually staged in order to do semantic and conversational analysis, to highlight and enumerate some very relevant words (suggested or "for- 
PAPER

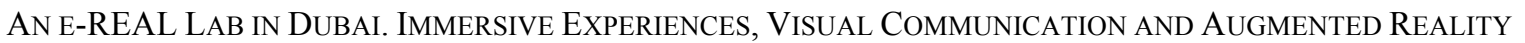

bidden"), to track tone and volume of the voice, as well as pace and pauses. Moreover, we utilize video monitoring and recording of facial expressions and body language, activating many times a mirroring function to foster people's awareness. In a nutshell: emotions, visual and perceptual thinking are central within e-REAL. Concepts that take shape, as well as emotions, become part of the discursive scenario thanks to several tools from cutting-edge discoveries in the neurosciences [13].

\section{Testing E-REAL: EvidenCE In THE FIELD}

Within an e-REAL lab such us the one installed at Etisalat Academy in Dubai, we primarily monitored a cluster of skills related to behavioral outcomes: active listening, asking open questions and knowledge sharing by metaphors easily understandable within the classmates' group. In addition, we monitored the ability to imitate relevant gestures in order to manipulate technical equipment. The monitoring methodology was the assessment center. Both of the authors of this paper were directly involved as assessors, within a team comprised of four assessors.

We assessed people, focusing on the same corecompetencies before the delivery in the e-REAL lab and during a follow-up (on average 2 weeks after the delivery). Our testing involved 64 people who voluntarily attended 4 different programs - on negotiation, scenario thinking, knowledge sharing in a matrix organization and safety on an oceanic oil exploitation platform. Each program involved 2 different groups, comprised of 8 people each. For each program, one group was involved within an e-REAL lab (4 projected surfaces with multimedia contents available during that time +2 iPads available during the sub-group's activity), with a second group attending a more traditional learning setting (a classroom with only one projected surface with multimedia contents made available depending on the instructor's decision).

The same instructor was involved both within e-REAL and in the traditional classroom. The "deliverables" were the same. The working language was English (better: "global English") and 100\% of the attendees did not have English as their mother-tongue to avoid inequality. The enrolled attendees' fluency in English was tested before kicking-off as an upper-intermediate. So, we can say that $48 \%$ is an average overall result reached after having attended an e-REAL program and that means that it is really effective and can be seen as a "killer application" if compared with the more traditional learning settings. Assessment of learning outcomes proves that 3 hours in the e-REAL immersive lab corresponds to 8 hours in a traditional training classroom.

e-REAL is designed to provide continuous feedback during the training session through tools tracking verbal and non-verbal communication, time, movements, postures and semantics. Real time feedback gives learners a better understanding about the way they behave, increasing their awareness and offering clear guidance on how to improve their capabilities. From an instructional design point of view, this means providing learning environments with multiple and varied resources and designing recursive fruition logics, so that the same subject can be represented by multiple, rather than singular, representations, each of which having its own form, perspective and conceptual dimension.

In Conclusion: e-REAL is highly effective primarily with regards to the following different aspects:

a) Training Duration and Effectiveness: all e-REAL programs are designed to facilitate the learning process. assessment of learning outcomes proves that 3 hours in the e-REAL immersive lab corresponds to 8 hours in a traditional training classroom.

b) Situated Learning: learners are immersed - mind and body - in realistic training scenarios that reflect the way knowledge has to be sourced and shared in real life, allowing experimentation through sensing, thinking and acting for a deep learning, fostering at the same time soft and technical skills.

c) Simplicity: Learning with e-REAL is simple. All the contents are presented and visualized in a way that fosters comprehension and engages attention. Diagrams, maps, charts, images, video and data visualizations all help learners in understanding complex concepts in an easy way.

d) Serious Gaming and Active Involvement: e-REAL offers an effective game-based learning environment, rising participation and a method that keeps the users focusing for longer periods of time. Learners who are actively engaged promote collaborative construction of knowledge and this allows for better memorization. Learners work toward a goal, choosing actions and experiencing the consequences of those actions along the way, making mistakes in a risk-free setting and then practice different ways to do things.

e) 360 Feedback: e-REAL provides continuous feedback during the training session through tools tracking verbal and non-verbal communication, time, movements, postures and semantics. Real time feedback gives learners a better understanding about the way they behave, increasing their awareness and offering clear guidance on how to improve their capabilities. From an instructional design point of view, this means providing learning environments with multiple and varied resources and designing recursive fruition logics, so that the same subject can be represented by multiple, rather than singular, representations, each of which has its own form, perspective and conceptual dimension.

In Summation: Learning with e-REAL is simple. In the e-REAL ecosystem, all of the contents are presented and visualized in a way that fosters comprehension and engages attention. Diagrams, maps, charts, images, video and data visualizations all help learners in understanding complex concepts in an easy way. It allows us to link different representations of the same information (critical thinking). e-REAL offers an effective game-based learning environment, rising participation and a method that keeps the users focusing for longer periods of time. Learners who are actively engaged, promote collaborative construction of knowledge and this allows for better memorization. Learners work toward a goal, choosing actions and experiencing the consequences of those actions along the way, making mistakes in a risk-free setting and then they practice effective ways to do things. 


\section{REFERENCES}

[1] T. Piketty, Le Capital au XXIe siècle, Éditions du Seuil, Paris, 2013.

[2] J. Stiglitz \& B. Greenwald, Creating a Learning Society, Columbia University Press, New York.

[3] F. Salvetti, Rethinking learning and people development in the $21^{\text {st }}$ century: The Enhanced Reality Lab-e-REAL - as a cornerstone in between employability and self-empowerment in F. Salvetti, M. La Rosa \& B. Bertagni (Eds.), Employability. Knowledge, Skills and Abilities for the "Glocal" World, Angeli, Milan, 2014.

[4] J. Stiglitz \& B. Greenwald, Creating a Learning Society, Columbia University Press, New York; B. Bertagni, M. La Rosa \& F. Salvetti (Eds.), Learn How To Learn! Knowledge Society, Education and Training, Angeli, Milan, 2010.

[5] Etisalat Academy, headquartered in Dubai, is the largest singlesource business and telecom training solutions provider in the Middle East. For 30 years it has been providing training consultancy and human capital development services to telecoms, government agencies, oil \& gas companies, financial institutions and organizations across all industries and business sectors.

[6] R.K. Sawyer (Ed.), The Cambridge Handbook of the Learning Sciences. Cambridge University Press, Cambridge, 2006; D. Shell, D. Brooks, K. Wilson, D. Kauffman \& L. Herr, The Unified Learning Model. How Motivational, Cognitive and Neurobiological Sciences Inform Best Teaching Practices, Springer, Heidelberg, 2013; H. Gardner \& K. Davis, K., The App Generation: How Today's Youth Navigate Identity, Intimacy, and Imagination in a Digital World, New Haven and London, Yale University Press, 2014.

[7] M. Merleau-Ponty, La nature de la perception, 1934, in Le primat de la perception et ses conséquences philosophiques, Éditions Verdier, Lagrasse, 1996.

[8] The Works of Jeremy Bentham (edited by John Bowring), vol. 4, William Tait, Edinburgh, 1843.

[9] M. Foucault, Surveiller et punir, Gallimard, Paris, 1975.

[10] E. Morin, La connaissance de la connaissance, Le Seuil, Paris, 1992.

[11] S. Bresciani \& M. Eppler, “Glocalizing” Visual Communication in Organizations: When and How to Adapt Visual Communication to Local Standards, in: B. Bertagni, M. La Rosa \& F. Salvetti (Eds.), "Glocal" Working. Living and Working Across the World with Cultural Intelligence. Angeli, Milan, 2010; M. Eppler, H. Forbes Öste \& S. Bresciani, An Experimental Evaluation on the Impact of Visual Facilitation Modes on Idea Generation in Teams. London: IEEE Proceedings of the $16^{\text {th }}$ International Conference Information Visualization IV13, 15-18 July 2013.

[12] B. Bertagni \& S. Salvetti, Dealing with complexity in a simple way: How visualization boosts understanding in learning process. The Z Generation case, in F. Salvetti, M. La Rosa \& B. Bertagni (Eds.), Employability. Knowledge, Skills and Abilities for the "Glocal” World, Angeli, Milan, 2014.

[13] L. Nummenmaaa, E. Glereana, R. Harib and J. K. Hietanend, "Bodily maps of emotions," Proceedings of the National Academy of Science of the United states of America, 12-26, 2013; R. Gross, Psychology. The Science of Mind and Behaviour, Hodder, London, 2010; M.J. Friedlander, L. Andrews, E.G. Armstrong, C. Aschenbrenner, J.S. Kass, P. Odgen, R. Schwartzstein, T.R. Viggiano, "What can medical education learn from neurobiology of learning?", Academic Medicine, 86-4, 415-420, 2011; D.E. Feldman, "Synaptic mechanism for plasticity in neocortex", Annual Review of Neuroscience, 32, 33-55, 2009; F. Salvetti \& B. Bertagni, "e-REAL: Enhanced Reality Lab", International Journal of Advanced Corporate Learning, 7-3, 41-49, 2014. http://dx.doi.org/10.1073/pnas.1321664111

\section{AUTHORS}

Fernando Salvetti is with LKN-Logos Knowledge Network, Lugano and Bern, Switzerland, as well as with the University of Milan Bicocca, Milan, Italy and with the LUISS Business School, Rome, Italy. He was with the University of Bologna and the University of Turin (email: salvetti@logosnet.org).

Barbara Bertagni is with LKN-Logos Knowledge Network, Lugano and Bern, Switzerland. She was with the University of Milan Bicocca and the University of Turin (e-mail: bertagni@logosnet.org).

This work is an extended and modified version of a paper presented at ICELW 2015, the International Conference on e-Learning in the Workplace, held from June 10-12, 2015 at Columbia University in New York. Submitted, 30 July 2015. Published as resubmitted by the authors 30 August 2015. 